\title{
How do we create lasting and radical change in post-14 education?
}

\section{Michael Atkinson \\ The University of Sunderland SUNCETT}

\author{
Kate Duffy \\ The University of Sunderland
}

\begin{abstract}
This work reports on a conference held by SUNCETT (University of Sunderland Centre for Excellence in Teacher Training) held in May 2009. The event, which involved keynotes from Professor Michael Fielding and Professor Frank Coffield, explored notions of collaborative practice between colleagues in the post compulsory sector. In drawing on the experiences of the many practitioners who attended the conference, the paper concludes that a more sustainable sector is possible where trust is nurtured; time, space, and designated places are provided for practitioners' development; where open and frequent dialogue between colleagues, and staff and learners is established; and where a greater sense of a combined vision and shared values is created.
\end{abstract}

Key words

Joint Practice Development; Shared Values and Vision; Professional Spaces and Places; Teacher Voice; Sustainable Practice.

\section{Introduction}

"Any intelligent fool can make things bigger, more complex, and more violent.

It takes a touch of genius, and a lot of courage, to move in the opposite direction"

Albert Einstein ${ }^{1}$

This piece of work brings together key highlights from SUNCETT's spring conference, held at Seaham Hall in May 2009. It aims to consolidate and communicate not only what was conveyed in the contributions from the keynote speakers, Michael Fielding and Frank Coffield, and from the responses, questions, and discussions that those present brought to the day, but to discuss how 'lasting and sustainable change in post-14 education' might be possible.

Training providers, teachers, teacher educators, and senior managers from the North East of England made up those attending the conference. Many members of the audience said they felt inspired and encouraged by the discussions that took place, and expressed their gratitude for the opportunity to share understandings and issues raised by the two speakers; issues that are very real for them in their day-to-day work in the sector. Feedback suggests that many left the conference with a renewed sense of hope and opportunity in acting for change, with one participant commenting:

"Very inspirational - this morning's talk, has motivated me into wanting to make 'change' within my sector"

It is one of SUNCETT's key roles to provide such opportunities to encourage practitioners in the sector to think and talk carefully and critically about who they are, who they have been and who they could be, and this conference showed that this is no longer just a notion aspired to by SUNCETT, but a real lived experience for those involved in SUNCETT events.

Of the discussions, presentations, and debates that took place at the conference, three themes emerged that will be the focus of this paper: shared values and vision, democracy, and sustainability. The theme of shared values and vision will be explored due to views expressed at the conference in relation to employees, employers, and learners regaining a sense of purpose, community and coherence in the sector. Building upon this theme, the notion of democracy is discussed due to a general consensus at the conference that conditions for dialogue and debate are currently limited in our institutions. As one audience participant remarked:

"I don't feel brave enough to take ideas back to college ... there may be repercussions"

If we desire spaces, places and time to collaborate and to have a voice in educational matters, then perhaps we need to explore what it means to be democratic, and whether it has value in the process of positive change in the sector.

Finally, in drawing upon many of the issues raised at the conference, we will attempt to 'unpack' the notion of sustainability with an exploration of what practices and attitudes might be desirable and attainable for the long-term stability and success of the sector.

We hope that this paper can form the beginning of an open, meaningful and purposeful dialogue between colleagues in the sector. We draw on the works of both Michael Fielding and Frank Coffield, those present at the conference, and other colleagues in the sector, to help us begin.

What kind of change are we looking for in post-14 education?

\footnotetext{
${ }^{1}$ http://rescomp.stanford.edu/ cheshire/EinsteinQuotes.html (Accessed 16 October 2009).
} 
Whilst many issues within the sector have been discussed, written and thought about in some depth in the literature already, repeating them at any great length may serve no great service to the readers of this paper. Instead this work is meant to stimulate activity towards positive change, working on the assumption that employees and employers in the sector, and perhaps learners too, already have within their means the resources to do so, despite real barriers. The spirit of this aspiration is perhaps mirrored in the following comments from members of the conference audience:

"The session made me think about the need to be brave, to challenge and to persuade others that things can be done differently"

and:

“Thought provoking, given me the impetus to challenge systems that aren't meeting learners' needs"

Nevertheless, we will briefly highlight some of the concerns and queries that, not only have been repeatedly voiced by those who have attended SUNCETT conferences over the last few years, but which have been written about extensively in the literature. We will do so to give some context to our arguments, as well as to inform those who are not so familiar with them.

Whilst employees in the sector remain concerned about the cultures within which they work, those at the conference were seemingly of one mind with regard to particular issues. Firstly, time, and the lack of it was expressed repeatedly, not only in relation to Continuous Professional Development, planning, and other duties, depending on a person's role, but personal time and time for building relationships within the workplace. Sufficient time is of course important if colleagues and learners are to engage with each other in meaningful and lasting ways. Without it, professional relationships, the development of resources, and one's engagement with learners on a one-to-one basis, to name but a few examples, may produce superficial outcomes that do not tackle the problem or produce the desired results.

For Michael Fielding, time for employees to work thoughtfully together may not only lead to pedagogically sound resources and ideas, but also build teams that learn to trust each other. Such relationships, he suggests, need time to grow and this can take a substantial amount of time, even years, to establish those important links of mutual trust. This may require us to reconsider the value of time, to take it seriously as a significant factor in pedagogical and institutional improvement. As he says:

$$
\begin{aligned}
& \text { '...the work of transfer has to be sustained over time. It is not a quick fix. It requires a more sophisticated and more patient } \\
& \text { understanding of time than is customarily acknowledged or allowed.' }
\end{aligned}
$$

(Fielding, 2005: p. 5)

Secondly, and linked very closely with time, is the need for spaces and places within institutions for staff to meet with each other to discuss teaching and learning and generally to get to know each other. Only a few members of the audience agreed that dedicated spaces were currently allocated for professional discussions in their institution, and in these it was a shortterm funded project that made this possible. On the whole, participants expressed the severe lack of, and premium value of such spaces, not only to hold formal professional discussions, but informal conversations, both professional and personal with colleagues and learners alike. During group feedback, for example, the following was expressed:

"Informal spaces are important - we haven't got this or time to actually have...meetings (for professional discussions). It has come down to talking about these things over a cup of tea"

If such spaces were to be provided, where people can 'grow' relationships; can build trust, and can collaborate on ventures of mutual, professional interest to them, such as the development of resources or action research, for example, then this can only be good for the profession (see Fielding, 2005). As we will discuss later, these are places where initiatives and performance targets can be complemented by autonomous professional decisions and reflections, and where pedagogical judgements can once again be debated.

Finally, and by no means the only other issue, was the expressed desire to have a voice - for practitioners at all levels to be able to communicate their needs and concerns, and to have a say in the decisions that affect them and their learners. Many saw the conference itself as an opportunity for such expression, as this quote from one participant testifies:

"This conference is part of giving us a 'teacher voice'. Our 'teacher voice' is being valued by colleagues and is taking us forward"

The importance of being allowed a critical voice was also explored; the need for open and honest relationships, and the necessity for practitioners to enter a two-way dialogue with senior managers, executive, and policymakers, as a pre-requisite for a healthy and vibrant sector. Our section on democracy will look at the implications of these points in more depth.

\section{Shared values and vision \\ "Get your principles straight and the rest is a matter of detail"}

Napoleon ${ }^{2}$

What is our vision for education? Do we have a vision? Have we ever been asked to consider what the aims and purposes of education are? When we do our work, do we connect with an ideal of any sort? Are we planning for social justice, for

\footnotetext{
${ }^{2}$ http://www.napoleon-series.org/research/napoleon/c_quotes.html (Accessed 18 October 2009).
} 
instance, or are we just planning another lesson so that learners can pass a course? Do the Government have the same vision as its many quangos? Does this vision align with the vision of institutions, teachers, learners, Human Resource departments and principals, or even our communities? Is it likely that in a pluralistic society there could be such widespread and deep agreement over values?

In his publication, Running Ever Faster Down the Wrong Road: An Alternative Future for Education and Skills (2006), Coffield outlined his criticisms of the recent PCET landscape. He argued that the sector has been in a state of fragmentation, and that the way in which it is organised is now 'doing more harm than good' (Coffield, 2006: p. 2). The sector, he claimed, is 'composed of a number of interrelated sub-systems, each of which is more or less organised or disorganised' (ibid: p. 7). This perhaps is not news to the Government, for it was only recently in the report, Realising the Potential: A Review of the Future Role of Further Education Colleges (2005), that they showed recognition that the sector 'lacks a clearly recognised and shared core purpose' (Foster, 2005: p. 7).

With the pace of change and complex nature of the sector and the changing nature of what is best for the sector at any one time, it is perhaps difficult to find an enduring sense of purpose and coherence in the system (Keep, 2006). As Coffield again pointed out:

Policies have not only evolved or been radically altered, as Secretaries of State and senior civil servants have come and gone, but some policies were abandoned, while others were from the start internally inconsistent or flatly contradicted existing policies.'

(Coffield, 2006: p. 4)

One recent example of this is the 2008 response to the Leitch report, 'Re-skilling for recovery: after Leitch, implementing skills and training policies', which reconsiders the aims of the Leitch review of 2006, in light of the current economic downturn (House of Commons, 2008).

It is unclear to what extent the organisations that make up our sector not only discuss their educational values, but align their values with each other, with the values of educators, and what is valued in society. Feedback from the conference highlighted that, at least in some cases, individuals working in the sector feel that there are just not the opportunities to explore what the purposes and values of education are. Whilst it is perhaps important that the education system as a whole works towards an agreed goal, it is just as important that individuals and departments within an educational institution find some way of developing a common purpose and direction that is valued by all its members. Deciding what this is may be no easy task. However, there may be no better way to begin than by ensuring that teaching and learning becomes the first priority of the sector (see Coffield, 2008), but also the priority of all individuals within our organisations. As one conference participant suggests:

"All systems and structures should be focused towards good quality teaching and learning. Administration staff also need to know about teaching and learning, so they create the right system".

What, for many, complicates this issue, however, is the advent of teaching and learning initiatives that are regularly promoted by government, and that which, at times, may conflict with the values and goals of individual practitioners. Educational literature, including policy, for example, is littered with new ideas, strategies, and whole systems that provide the guidance for how to get from A to B in ten small steps. The promulgation of Individual Learning Plans (ILPs) in the Government's recent 'personalisation' agenda (see TES, 1 December 2006) for example is one such approach to pedagogical practice; the irony is, as Johnson and Hallgarten point out, that real pedagogical concerns are pushed aside whilst practitioners strive to accommodate and assimilate such new 'prescribed' methodologies (Johnson and Hallgarten, 2002: p. 238). Biesta goes further when he says:

'...educational practice is more than the simple application of strategies or techniques to bring about predetermined ends - there is always the question about the desirability and educational value of such strategies'

(Biesta, 2007: p. 18)

There is perhaps nothing inherently wrong with any such initiatives. Policy, for instance, is packed with good intentions; Lord Leitch's goals of economic prosperity and social justice chime well with many of our own beliefs about education (Leitch, 2006), and can even make us feel a sense of momentary pride in our profession - "it can do a great deal of good in the world", we may think, and "I can make a difference". Yet, it is perhaps true for many teachers that, despite the value of certain initiatives, the time, space and energy needed to make them pedagogically worthwhile cannot always be maintained as other pressures creep in. ILPs for example may become a technical exercise; another piece of paperwork, or a "'tick-box' exercise" as one conference participant noted.

Initiatives such as these, and the way they are designed, communicated and built into practice, may then prevent them from having the intended impact (see also Hamilton, 2009: p. 236). This is what Fielding means when he says that practices become meaningless. "Reflective professional enquiry", he says, "loses meaning (with) too much emphasis on external frameworks" (Conference talk). From this we perhaps lose a sense of why we do what we do, and what greater vision it fits into; whether it be social justice or economic prosperity. The following comment from a member of the conference audience may go some way to support this point: 
'It seems we all do want to 'be better' at what we do. Regulations, inspections and such limit our creativity and approaches. We need to get back to basics, achieve targets but remember the target is the achievement of learning not just financial and management targets"

Perhaps it is time to assert a new model of working together over time which recaptures a professional ethos in our sector that sustains practices and makes them real, meaningful and worthwhile. Michael Fielding's notion of Joint Practice Development (JPD) may be one such way in which we can regain a sense of mutual understanding and direction in pedagogical matters. Rather than the incessant relay of 'what works' or 'best practice' from those whose work has been officially recognised as 'excellent', practitioners should instead develop understandings and resources together in collaboration. According to Fielding's research, this way of working imbues the transfer of practice with meaning, and is more sustainable in the long term, leading to trust and a sense of personal and institutional identity (Fielding, 2005: p. 5).

Sustainable and nurturing practices such as this may, in the long term, counter what Richard Sennett describes as the 'competitive obsession' through which people 'lose sight of the value and purpose of what they are doing' (2009: p. 251). Perhaps even a sense of common purpose can begin to emerge from a new understanding of what it means to truly work together professionally in a mature and intelligent manner. Building trust and nurturing understanding together is likely to be more sustainable, and better for the profession, than the current climate of competitiveness and insecurity (see Whitty, 2005: p. 11). However, for this to occur, there is perhaps a need for spaces, time, and opportunities to share practice, concerns and understanding in a more democratic way, as the next section explores.

\section{Democracy: where are the spaces for restless encounter?}

'An individual does not become a professional in isolation'

(Dall'Alba, 2009: p. 42)

Responses given at the conference suggest that in this sector, professional practitioners struggle to find the time and space for collaboration and open discussion with each other. For some, this shows in the lack of two-way dialogue between teachers, managers and senior managers; for others, the lack of space, and therefore opportunity, to engage in such dialogue. One participant remarked that "these spaces are being squeezed"; and there was considerable agreement amongst the audience that such opportunities are vital to both their personal and professional well-being, to the experiences of their learners, and to the health of their institutions in general.

Whilst we may not be able to assert that democracy within institutions will constitute the ideal scenario for a thriving post14 sector, it is difficult to ignore that the issues raised at the conference deeply matter to those who were present.

There is much to say in the literature about 'voice'; 'student voice' and 'teacher voice', for example, are discussed by Michael Fielding and Coffield to some length (Fielding et al, 2005; Fielding and McGregor, 2005; Coffield, 2009). Having input into the decisions that affect us is certainly something that many value, and is democratic by nature. The SUNCETT conference itself, as noted earlier, was seen by some as an opportunity for voices to be aired, and many found this refreshing and stimulating, and not something they were used to. There was, to some extent, a frustration in the comments made about staff sharing their concerns in their institutions, with one participant commenting that staff need to "feel comfortable expressing views" and another suggesting that "teachers need the support of SMTs to empower the changes". These are not passing comments, but genuine concerns voiced from people placed well to observe what isn't working in their institutions. That being said, it is important to consider the two-way nature of dialogue, and therefore the need for all parties within an institution to meet and talk on an equal basis in order to understand each other's predicaments.

\section{So what are the options?}

Michael Fielding's question, "Where are the spaces for restless encounter where we come to re-see each other and open up new possibilities?" (Conference talk), points towards a more healthy and nurturing dynamic within the learning community; one that creates a climate of collegiality and mutual trust. For professionals to re-engage in meaningful dialogue regarding pedagogy that is untouched and unhindered by systems that are often unhelpful to both staff and learners in educational institutions, would surely be welcome. As mentioned earlier, Fielding's notion of JPD can perhaps play its part in building bridges towards a more collaborative culture within and across institutions, if only for teaching practitioners in the first instance. In the short term, and, as one member of the audience suggested, it may be useful for us to look for funding that will enable at least the beginnings of the cultures we desire to create. Again, Fielding highlights how:

'...central...the deployment of financial resources [is] to enable the transfer of initiatives to get off the ground and...to sustain them over a sufficient period of time for them to be productive and worthwbile.'

(Fielding et al, 2005: p. 38)

As funding is not always available, we can perhaps instead take Coffield's advice, and begin to "show interest in colleagues' thoughts and interests, and think about working together" (Conference talk). We can, in other words, proactively engage with our colleagues with an aim to find mutual interests and work to improve what we do together. 
Whilst we may have witnessed the demise of the staff-room in recent times, where colleagues both relaxed and discussed teaching and learning, perhaps it is time to re-think what spaces would be most beneficial for an effective and sustainable community of learning in the post-14 sector. In discussing the relationship between student and teacher, Fielding remarks:

It will not be long before we see imaginative examples of new spaces emerging in schools where students and teachers acknowledge and delight in their mutuality, in their reciprocal responsibilities for the world we live in now and the world we wish it to become, in their 'radical collegiality.'

(Fielding, 2004: p. 310)

Perhaps this kind of sensibility can begin to pervade our sector and the relationships between all members of staff at all levels. At the same time, and if we are to meet Fielding's vision, we may need to ensure that the practices we develop are sustainable in order to meet the long-term needs of learners, ourselves, and the communities we serve. We will briefly turn to this topic now as part of our conclusion.

\section{Conclusion and recommendations}

The notion of sustainability is one that is often associated with the environment, and the drive to extract and utilise natural resources from the earth and sea at a level that is sustainable over a long period of time. In terms of the discussion here the principle is the same: what conditions do we need to establish for the long-term benefit of our institutions, ourselves, our learners, and society?

Whilst Coffield has argued against the way in which government ministers are regularly reshuffled and how 'such constant movement disrupts working relationships, prevents the deep understanding of the challenges faced by particular Ministries and promotes short-term thinking and action' (Coffield, 2006: p. 20; see also Bridges, 2008: p. 473), members of the conference audience commented similarly on the turnover of staff in their institutions. As one conference participant commented, "we need to go back to basics, keeping staff on board is difficult. There is too much turnover, and this leads to a lack of trust"; a point reflected by Richard Sennett when he asks:

How can mutual loyalties and commitments be sustained in institutions which are constantly breaking apart or continually being redesigned?'

(Sennett, 1998: p. 10)

Long-term trusting relationships built on years of working together are surely what learners and employees need, if desirable educational goals are to be fulfilled (see Fielding, 2005). But this is not going to come too easily when, as a conference participant noted, courses are often vulnerable to changes in funding: "I am not sure if funding is going to be on-going. Such uncertainty leads to low morale"

What was key with regards most of the discussions at Seaham Hall was the need for practitioners at all levels to maintain a sense of self-worth over time, so that 'individual identity will be preserved in the midst of change' (Bierema, 2008: p. 59). This in turn will surely benefit the learners and the institution as a whole.

The notion of a sustainable education in the sense discussed here perhaps belongs to the next step in this discussion. But it was highlighted here as a theme implicit in much of the issues discussed. Building trust; creating spaces for long-term professional relationships; giving more time to staff to nurture themselves both personally and professionally; greater dialogue between SMTs and teaching staff and between staff and students, and ensuring they feel valued, are all factors that may contribute towards a more sustainable and fruitful post-14 sector.

The following recommendations are based on the above discussion, and comments made at the conference. They point towards practical but realistic steps for improvement.

- Find ways to collaborate with colleagues to share ideas and practices. Promote a culture of JPD throughout your institution that draws on a wide range of knowledge and expertise.

- Look for research opportunities that have funding attached to them. This may enable opportunities for change.

- Create more spaces for dialogue between staff at all levels, and between teaching staff and learners. Spaces that enable opportunities for staff to meet on a regular basis, get to know each other and build personal and professional relationships, and spaces in which learners can enter into effective dialogue with teachers, and other members of staff.

- Show interest in what your colleagues are doing, and search for opportunities to work together on ventures of mutual interest.

- Develop a culture for practitioners to participate in meaningful dialogue around pedagogical issues, and to carry out research so that a rich professional community can develop. This will hopefully lead to long-lasting trust between colleagues and a stronger commitment to their institution.

- Develop modes of practice that ensure that teaching and learning is always at the heart of decision-making.

- Find ways to re-connect with your values and share understandings about the purpose of education, the mission of your institution, and your particular role in relation to these goals. Keep up to date with policy changes and discuss the extent to which your roles and values may align with them. This would perhaps be most effective if discussed across your institution. 
If you would like to share some of your thoughts regarding the content of this report please email us at: michael.atkinson1@sunderland.ac.uk and kate.duffy@sunderland.ac.uk. In helping to refine and test the validity of the issues raised here, your views are valuable to us, and will be carefully considered in light of further discussion in the future.

\section{References}

Biesta, G. (2007) 'Why “What Works” Won't Work: Evidence-Based Practice And The Democratic Deficit In Educational Research', Journal of Educational Theory Vol. 57, No. 1, pp. 1-22. http://dx.doi.org/10.1111/j.1741-5446.2006.00241.x

Bierema, L.L. (2008) 'Adult Learning In The Workplace: Emotion Work Or Emotion Learning?’, Wiley Periodicals: New Directions for Adult and Continuing Education No. 120, pp. 55-64.

Bridges, D. (2008) 'Educationalisation: On The Appropriateness Of Asking Educational Institutions To Solve Social And Economic Problems', Journal of Educational Theory Vol. 58, No. 4, pp. 461-474. http://dx.doi.org/10.1111/j.1741-5446.2008.00300.x

Coffield, F. (2006) Running Ever Faster Down the Wrong Road: An Alternative Future for Education and Skills. Inaugural Lecture. London: Institute of Education. Coffield, F. (2008) Just Suppose Teaching and Learning Became the First Priority. London: Learning and Skills Network.

Coffield, F. (2009) All You Ever Wanted to Know About Learning and Teacbing But Were Too Cool to Ask. London: Learning and Skills Network.

Dall' Alba, G. (2009) 'Learning Professional Ways of Being: Ambiguities of Becoming', Journal of Educational Philosophy and Theory Vol. 41, No. 1, pp. $34-45$. http://dx.doi.org/10.1111/j.1469-5812.2008.00475.x

Fielding, M. (2004) 'Transformative Approaches To Student Voice: Theoretical Underpinnings, Racalcitrant Realities', British Educational Research Journal Vol. 30, No. 2, pp. 295-311. http://dx.doi.org/10.1080/0141192042000195236

Fielding, M. et al (2005) Factors Influencing the Transfer of Good Practice. Sussex \& London: University of Sussex and Demos.

Fielding, M., McGregor, J. (2005) Deconstructing Student Voice: New Spaces for Dialogue or New Opportunities for Surveillance? Montreal: AERA.

Foster, Sir A. (2005) Realising the Potential: A Review of the Future Role of Further Education Colleges. Nottinghamshire: DfES publications.

Hamilton, M. (2009) 'Putting Words In Their Mouths: The Alignment Of Identities With System Goals Through The Use Of Individual Learning Plans', British Educational Research Journal Vol. 35, No. 2, pp. 221-242. http://dx.doi.org/10.1080/01411920802042739

House of Commons (December 2008) Re-Skilling For Recovery: After Leitch, Implementing Skills And Training Policies. London: The Stationery Office Limited. Johnson, M., Hallgarten, J. (eds) (2002) From Victims Of Change To Agents Of Change: The Future Of The Teaching Profession. London: Institute for Public Policy Research.

Keep, E (2006) 'State Control Of The English Education And Training System - Playing With The Biggest Train Set In The World', Journal of Vocational Education and Training Vol. 58, No. 1, pp. 47-64. http://dx.doi.org/10.1080/13636820500505819

Leitch, S. (2006) Prosperity For All In The Global Economy: Final Report. London: HM Treasury.

Sennett, R. (1998) The Corrosion Of Character: The Personal Consequences Of Work In The New Capitalism. London \& New York: W. W. Norton \& Company. TES (1 December 2006) http://www.literacytrust.org.uk/database/Secondary/personalised.html [Accessed 5 June 2009].

Whitty, G. (2005) 'Moving Beyond Recent Education Reform - And Towards A Democratic Professionalism', Paper, International Symposium On Education Reform And Teachers, Tokyo, Japan: Hitotsubashi University. 